\title{
INTERNET O EL FUTURO DE LA PUBLICIDAD LOCAL
}

\author{
Magdalena Mut Camacho: Universitat Jaume I (España)
}

\section{Introducción}

Una definición de las ventajas de la publicidad podría ser que ésta sirve para fortalecer los vínculos entre el consumidor y el producto o la marca; pero esta regla que rige para cualquier tipo de producto o servicio, independientemente del ámbito geográfico en el que se halle enmarcado, encuentra un difícil acomodo en el ámbito local.

¿Por qué? Muchos son los inconvenientes que encontramos en el desarrollo profesional, como sinónimo de eficaz, de una publicidad en el ámbito local: agencias poco profesionalizadas, por no decir poco profesionales; nulo conocimiento por parte del anunciante de los beneficios de la publicidad; medios de comunicación locales que sólo venden espacio o tiempo publicitario; nulo trabajo de investigación de mercado; poca confianza en las ventajas de la comunicación comercial.

Sin embargo, ante todo este panorama, Internet se puede convertir en una buena solución para los anunciantes locales que pueden ver como sus productos y servicios se anuncian de una forma eficiente e interesante, pues puede ofrecer a sus potenciales consumidores otras ventajas que la publicidad convencional no permite, y con un factor determinante, con una inversión prudente.

¿Con qué ventajas contamos?

Se ha demostrado que la publicidad en Internet es rentable para los anunciantes. La profesora de Nuevos Medios Publicitarios de la Universidad de Navarra, Noelia Fernández Arroyo, en el II Congreso Internacional sobre Medios de Comunicación en Internet presentó un estudio que señalaba que la publicidad en Internet "es más eficaz y potencia mejor la venta y la idea de marca que otros medios, como la radio o la televisión".

- Cada vez más gente reserva más tiempo para conectarse a la red.

- El mensaje publicitario puede ser mejor y más efectivo.

- La interactividad del medio

- La posibilidad de medición

- La versatilidad de la comunicación

- La posibilidad de vender on line

- Las ventajas tecnológicas; ahora la tecnología avanzada permite diferenciar segmentos geográficos y permite reconocer el número de área del número telefónico del visitante y determina su ubicación geográfica.

Al combinar todo esto con la atención que Internet recibe ahora y su papel cada vez mayor en la vida de los consumidores, podemos pronosticar que la publicidad local en la Web puede dar un gran salto. 
Pero, ¿con qué inconvenientes contamos? Varios:

- El limitado número de sitios que pueden dar servicio a los anunciantes locales

- La reticencia inicial respecto a un nuevo medio de comunicación

- Una audiencia limitada por la necesidad de contar con ordenador personal

- Y un mal servicio por parte de la compañía proveedora de servicio telefónico.

\section{Panorama actual de la pyme en relación a Internet.}

Consideramos en este análisis sobre los beneficios de la publicidad local que en su gran mayoría sus usuarios son las pymes locales. Un estudio realizado por la Confederación General de Pequeñas y Medianas Empresas del Estado Español (COPYME) señala en sus conclusiones que el $36,3 \%$ de las pequeñas y medianas empresas españolas no emplea en su trabajo diario Internet ni el correo electrónico, también señala que el comercio electrónico ocupa un lugar residual en la actividad cotidiana de estas compañías.

Este informe titulado "Impacto de las Nuevas Tecnologías y de la0Sociedad de la Información en las pymes. Incidencia sobre la cualificación profesional de los trabajadores'" apunta que sóho un tercio de las pymes españolas emplea nuevas tecnologías específicas para su sector, una de cada cuatro prevé su utilización, mientras que casi la mitad de ellas ni siquiera lo tiene previsto. También explica que el comercio electrónico ocupa un lugar residual en la actividad cotidiana de las pymes españolas, pues únicamente lo utiliza el 18\% de las compañías estudiadas.

A todo esto añadimos las conclusiones proporcionadas por una encuesta de las Cámaras de Comercio en el marco del Programa de Promoción de la Sociedad de la Información (Prince $X X I$ ) de donde se extrae que el $48 \%$ de\$las pequeñas y medianas empresas (pymes) con menos de 50 empleados disponen de su propia página Web y casi la totalidad, un $92 \%$ cuenta ãon ordenador para su gestión diaria.

Según la encuesta antes referida, dos de cada tres pymes disponen de dominio registrado en Internet y un tercio tienen página Web. De estas últimas, dos de cada tres admiten que no las actualizan nunca o sólo una vez al año.

Por tanto, observamos que las pequeñas y medianas empresas son reticentes a la hora de utilizar las nuevas tecnologías ya que se suscitan una serie de barreras, salvables por otra parte, que se pueden resumir en: la cautela de los clientes, la inseguridad del medio, la falta de formación de los empleados y la legislación insuficiente.

En este sentido encontramos iniciativas desde la administración con objeto de ir matizando este panorama y acercar a la sociedad española al mundo de la tecnología de la información.

Por parte de la administración, y más concretamente desde el Ministerio de Ciencia y Tecnología, se ponen en marcha iniciativas para solucionar esta situación en la que nos hallamos y ha puesto en marcha un plan llamado "España.es", donde los objetivos que persigue el plan, dotado con más de mil millones de euros, son 
eliminar la brecha digital, modernizar tecnológicamente a las pequeñas y medianas empresas españolas (pymes), y mejorar la seguridad y confianza mediante la firma y el DNI electrónicos.

Esto viene a refutar la importancia que tiene el pleno acceso a la Sociedad de la Información para mejorar la competitividad de las pymes, así como permitir que el conjunto de los españoles -independientemente de su edad, condición social y lugar de residencia- tengan un pleno acceso a los contenidos de las Nuevas Tecnologías.

Las administraciones públicas son conscientes de que el desarrollo de la Sociedad de la Información, y apostar por ella, es la mejor reforma económica, estructural y modo de garantizar la eficiencia en el funcionamiento de la economía, el desarrollo social del país y en la mejora de la igualdad de oportunidades para el conjunto de la ciudadanía.

En la provincia de Castellón, diez empresas asociadas al Centro Europeo de Empresas Innovadoras (CEEI) de la ciudad, están mejorando su sistema de gestión empresarial y sus relaciones comerciales con la incorporación de herramientas ebusiness (catálogo dinámico, tienda on-line, comercio electrónico).

La iniciativa, promovida y desarrollada por el Centro Europeo ha generado una inversión empresarial de cerca de 73.000 euros respaldada por el IMPIVA con 46.000 euros dentro de las líneas de actuación establecidas en el Programa Sociedad de la Información del Plan de Consolidación y Competitividad de la Pyme (PCCP); Plan financiado por la Unión Europea, el Ministerio de Economía y la Generalitat Valenciana.

En el terreno de las nuevas tecnologías de la información y la comunicación, es interesante gestionar ayudas en la línea de hacer de la información el hilo conductor de la cadena de valor de la pyme, integrando a los diferentes agentes implicados en la creación de conocimiento útil para el estímulo de la innovación. Y en todo este estímulo entra también su utilización en acciones de publicidad.

Las diez empresas que están participando en el proyecto del CEEl de Castellón han incorporado su catálogo de productos y servicios en la red. Estos les ha supuesto una reducción en gastos de impresión y la posibilidad de tener expuesta su oferta de forma continuada a un mayor número de usuarios. De igual modo a través de la función de gestor de pedidos las 10 pyme reciben de manera rápida, directa y actualizada sus nuevos pedidos pudiendo hacer un seguimiento en tiempo real de cada cliente.

¿Qué ventajas tiene para las empresas operar en Internet? Por un lado no sólo son ventajas competitivas sino ventajas en la eficiente gestión empresarial, ya que supone la incorporación del B2B y B2C en las empresas. También es una herramienta que elimina las barreras geográficas, que aporta dinamismo, interactividad y calidad a la gestión empresarial.

Otro de los beneficios que reportan estas herramientas es una reducción de costes, les permite diferenciarse de la competencia al tiempo que mejoran el servicio al 
cliente dando una respuesta más rápida a sus necesidades y expectativas.

No hay duda de que poco a poco nos encontraremos en un mercado que girará en torno a las nuevas tecnologías, el empresario ha de ser consciente de que Internet se ha convertido en una necesidad para todas aquellas empresas que quieran competir en un mercado global como el actual.

\section{Panorama actual de la publicidad local en Internet}

En Estados Unidos ya han comprobado la eficacia de Internet para la publicidad local, porque las centrales de medios interactivos como Flycast y DoubleClick, además de sites como Microsoft Sidewalk, están cortejando a las pequeñas y medianas empresas locales, así como a las grandes compañías, para que se anuncien a nivel local. Según la agencia McCann-Erickson, las inversiones en publicidad local representaron alrededor del 41 por ciento del total de gastos en publicidad en Estados Unidos en 1997.

Eso incluye la sección amarilla de los directorios telefónicos, anuncios exteriores, campañas directas de mercadotecnia y anuncios locales en radio, televisión y prensa impresa. Se espera que el número de anunciantes en la red sea cada vez mayor y que, por tanto, el presupuesto de publicidad aumentara significativamente.

\section{La situación en España de la publicidad en Internet}

Según los datos del 'IV Estudio sobre el Marketing y Publicidad en Medios Interactivos', presentado por la Asociación de Agencias de Marketing Directo e Interactivo ("http://www.agemdi.org/" It "_blank") sólo uno de cada tres anunciantes realizó durante 2002 algún tipo de publicidad a través de Internet, frente al $64 \%$ que no recurrió a ningún tipo de acción promocional 'on line'. Lo que supuso un incremento de 14 puntos respecto a 2001 y es congruente con la importancia que el medio interactivo está recibiendo por parte de las empresas.

El estudio revela que tres de cada cuatro compañías invirtieron menos de un cinco por ciento de su presupuesto general de comunicación en acciones publicitarias en Internet, de las que el 39\% invirtió menos de un 1\%. Estas cifras son consideradas "muy bajas" por el sector, lo que refleja que "sigue existiendo recelo" hacia los resultados que se obtienen de Internet.

Con respecto a los tipos de campañas publicitarias en Internet señala el estudio que las campañas de banners siguen siendo las que se llevan una mayor porción de las inversiones, con el 38 por ciento del total. A continuación aparecen las comunicaciones a través de correo electrónico (18\%), promociones (16\%), presencia en buscadores (11\%) q campañas desde sus propios sitios Web (9\%).

Según las estimaciones de la asociación, las empresas españolas invirtieron en 2002 71,2 millones de euros en medios interactivos en España, entre Internet y acciones a través de móviles, cifra que no es comparable a los 28,6 millones del año anterior, puesto que é\{ta hacía referencia exclusiva a la Red. 


\section{Conclusión}

A la vista de los diferentes datos que observamos, y que han ayudado a construir el marco actual sobre el que meditar, la publicidad en Internet se erige como trascendental atendiendo a cómo es el entorno en el que nos hallamos inmersos: individualización cada vez más selectiva de los consumidores, la saturación de impactos publicitarios, la fragmentación de las audiencias de los medios de comunicación, los avances en la tecnología de la informática personal.

Para la pyme local que necesita de una acción de publicidad eficaz, Internet se puede convertir en su mejor herramienta de comunicación. Para hacer encajar todo este puzzle es necesaria una reeducación del empresario y también de la audiencia/potencial cliente; necesita de una implicación activa (de acción física) y convencida (de acción subjetiva) por parte de todos. Esta implicación es importante en dos aspectos: 1) para el receptor del mensaje publicitario porque en Internet el mensaje permanece pasivo y es el individuo el que comportándose activamente tiene que descubriplo. 2) para el empresario local porque ha de estar convencido de que el objetivo es conseguir una relación más directa y sólida entre su empresa y su cliente, y esto sa puede conseguir gracias a la publicidad interactiva en Internet.

El diseño de una página Web puede llegar a ser un escaparate de la empresa para atraer a los visitantes y conseguir que repitan la visita periódicamente. Otra posibilidad de acción publicitaria en Internet, a nivel local, sería la de construir una galería comercial virtual, un espacio formado por varias empresas con los productos especializados de cada una pero con servicios conjuntos como distribución, servicio post-venta, pedidos, atención al cliente, etc. El campo, con las condiciones favorables, está abonado para la recolección de miles de ideas creativas y efectivas.

\section{Bibliografía}

DE SALAS, Isabel. La comunicación publicitaria interactiva en Internet. Fundación Universitaria San Pablo-CEU. Valencia, 1999.

ALONSO, Ma C. y otros. La sociedad española ante las nuevas tecnologías. Fundesco. Madrid, 1987.

BONSÓN, E. Internet empresarial. Editorial Ra-ma. Madrid, 1997.

LÓPEZ LITA, R. Comunicación de las empresas. Las nuevas obligaciones. Ediciones Ciencias Sociales. Madrid, 1990.

LÓPEZ LITA, R. Las agencias de publicidad: evolución y posicionamiento de futuro. Universidad Jaume I. Castellón, 2001.

http://www.el-mundo.es/navegante. 3 noviembre 1997.

http://www.elmundo.es/navegante/2003/07/15/esociedad/1058282009.html

http://www.elmundo.es/navegante/2002/08/16/empresas/1029497008.html 
Magdalena Mut Camacho

http://www.elmundo.es/navegante/2003/09/17/esociedad/1063801493.html http://www.impiva.es/__LYPERLINK "http://www.elmundo.es/navegante" http://www.elmundo.es/navegante. Diario del Navegante.19 de juliO de 1999 http://www.elmundo.es/navegante/2003/06/13/empresas/1055516396.html 